\title{
Article \\ Decline in Mobility: Public Transport in Poland in the time of the COVID-19 Pandemic
}

\author{
Michał Wielechowski ${ }^{1}$ (D), Katarzyna Czech ${ }^{2, *}$ (i) and Łukasz Grzęda ${ }^{1}(\mathbb{D}$ \\ 1 Department of Economics and Economic Policy, Institute of Economics and Finance, Warsaw University of \\ Life Sciences-SGGW, Nowoursynowska 166, 02-787 Warsaw, Poland; \\ michal_wielechowski@sggw.edu.pl (M.W.); lukasz_grzeda@sggw.edu.pl (Ł.G.) \\ 2 Department of Econometrics and Statistics, Institute of Economics and Finance, Warsaw University of Life \\ Sciences-SGGW, Nowoursynowska 166, 02-787 Warsaw, Poland \\ * Correspondence: katarzyna_czech@sggw.edu.pl
}

Received: 13 August 2020; Accepted: 25 September 2020; Published: 29 September 2020

check for updates

\begin{abstract}
The aim of the paper is to assess changes in mobility in public transport in Poland, as a consequence of the development of the COVID-19 pandemic. We analyse the problem from the country and regional (voivodeships) perspective. The data come from Google COVID19 Community Mobility Reports, the Ministry of Health of Poland, and the Oxford COVID-19 Government Response Tracker. The research covers the period between 2 March and 19 July 2020. The obtained results show that there is negative but insignificant relationship between human mobility changes in public transport and the number of new confirmed COVID-19 cases in Poland. The strength and statistical significance of the correlation varies substantially across voivodeships. As far as the relationship between changes in mobility in public transport and the stringency of Polish government's anti-COVID-19 policy is concerned, the results confirm a strong, negative and significant correlation between analysed variables at the national and regional level. Moreover, based on one factor variance analysis (ANOVA) and the Tukey's honest significance test (Tukey's HSD test) we indicate that there are significant differences observed regarding the changes in mobility in public transport depending on the level of stringency of anti-COVID-19 regulation policy both in Poland and all voivodeships. The results might indicate that the forced lockdown to contain the development of the COVID-19 pandemic has effectively contributed to social distancing in public transport in Poland and that government restrictions, rather than a local epidemic status, induce a greater decrease in mobility.
\end{abstract}

Keywords: COVID-19; coronavirus; pandemic; human mobility; public transport; government policy JEL Classification: I18; O18; R40; L90

\section{Introduction}

COVID-19 is an infectious disease caused by the severe acute respiratory syndrome coronavirus 2 (SARS-CoV-2), a seventh coronavirus that can spread between humans (Andersen et al. 2020). The World Health Organization (WHO) classified the COVID-19 epidemic as a global pandemic on 11 March 2020 (Maier and Brockmann 2020). The novel coronavirus pandemic has hit the global economy and societies on an unprecedented scale since the Great Depression (1929-1933), and is epidemically compared to the Spanish flu of the 1918 (Barro et al. 2020; Laing 2020). The scientists refer to the COVID-19 pandemic as the giant black swan phenomenon (Goodell 2020; Mazzoleni et al. 2020; Wind et al. 2020).

The spread of COVID-19 has resulted in a reduction in economic activity and led to significant threats to the financial stability of many countries in the world (Boot et al. 2020). The COVID-19 
crisis has shown both policymakers and the general public that natural disasters can create huge, global, direct, and adverse economic impacts (Goodell 2020). Nicola et al. (2020) show the strong, negative consequences of the pandemic in all sectors of the economy including primary, secondary and service sectors. The coronavirus pandemic has proven to be a formidable challenge for many European Union countries, including Poland (Czech et al. 2020; Goniewicz et al. 2020). According to Cochrane (2020), there is a strong need to create and implement a retail economy rescue plan that would prevent bankruptcies and insolvencies where possible.

The challenge facing the government is to choose an effective economic policy that meets the condition of social sensitivity. Jones et al. (2020) emphasize that governments' responses to the COVID-19 pandemic show a search for a balance between health and economic goals. According to Eichenbaum et al. (2020) the implementation of a restrictive policy preventing the spread of the coronavirus pandemic increases the depth of the recession and fiscal instability, but enables the achievement of an extremely important and fundamental goal, i.e., saving human lives. On the other hand, some researchers do not agree with the opinion that such strict restrictions and limitations should be introduced (Jelnov 2020).

The spread of the COVID-19 pandemic has caused the implementation of unprecedented measures restricting travel, movement and activity participation in many countries across the world (De Vos 2020). A variety of stringency policies, including stay-at-home policy, school, public institutions and workplace closures, cancellation of mass events and public gatherings, and restrictions on public transport have affected approximately $90 \%$ of the world's population, contributing to a general reduction in mobility on an unprecedented scale (Gössling et al. 2020). Tian et al. (2020) indicate that suspending public transport, closing entertainment venues, and ban on public gatherings are associated with reductions in case incidence. Jinjarak et al. (2020) show that countries with more stringent government policies have reported lower COVID-19 mortality growth rates. In their view, the relationship between the stringency of government policy and the mortality growth is negative and more pronounced in countries with older population, higher rates of urbanization, greater democratic freedom, and larger international travel flows. Yuksel et al. (2020) show that anti-COVID-19 policy adherence is not stable and fluctuates depending on the amount of information on COVID-19 that is available in a particular region and the level of risk aversion. In their opinion, the degree of social distancing depends on the government policy, particularly the social campaign affecting perception of the coronavirus pandemic by people in different regions. Bonaccorsi et al. (2020), Pepe et al. (2020), Pullano et al. (2020) and Queiroz et al. (2020) indicate significant relationship between human mobility and government restriction tightening to tackle the COVID-19 pandemic.

Warren and Skillman (2020) find that the COVID-19 pandemic has resulted in large reduction in mobility both in the US and globally. They indicate that half of the individuals in the entire state of New York spent most of their day within less than 100 feet from their initial position. Glaeser et al. (2020) show a visible decrease in urban mobility in USA accompanied by substantial heterogeneity both across space and time. Badr et al. (2020) reveal the mobility patterns are strongly correlated with decreased COVID-19 case growth rates for the most affected counties in the USA. Coven and Gupta (2020) and Almagro and Orane-Hutchinson (2020) find disparities in mobility responses to the COVID-19 pandemic rooted in income. Oztig and Askin (2020) show that countries with higher population density are found to be more likely to have more COVID-19 cases than other countries. Moreover, it should be emphasized that the strength of analysed relations also depends on the mobility reduction, which differs across nations and regions due to their initial mobility structure (Galeazzi et al. 2020).

Schlosser et al. (2020) find that in the aftermath of COVID-19 pandemic long-distance travel has been strongly reduced, having an effect on epidemic spreading processes by "flattening" the epidemic curve and delaying the spread to geographically distant regions. Cartenì et al. (2020) show that mobility habits are correlated with the number of COVID-19 infections. Similarly, Yilmazkuday (2020), based on daily Google mobility data covering 130 countries, claims that government stay-at-home policy is effective showing that lower mobility is associated with lower COVID-19 cases and deaths. 
However, Askitas et al. (2020), investigating mobility pattern across 135 countries, find that restrictions on internal movement, public transport closures and international travel controls do not lead to a significant decrease in new COVID-19 infections.

The article addresses the impact of the COVID-19 pandemic on the population-related mobility in public transport. The number and nature of interpersonal contacts between infected and healthy individuals affect the transmission of infectious diseases. Confined and crowded environments, including transport hubs, that are visited by people daily can become hot-spots for spreading infectious diseases (Goscé and Johansson 2018; Browne et al. 2016; Morawska et al. 2020). Public transportation vehicles, particularly buses, trams, trains and metros, which are used daily by millions of people, might contribute to the spread of infectious diseases among their users (Musselwhite et al. 2020; Troko et al. 2011). However, only a paucity of evidence describes SARS and MERS coronaviruses transmission events linked to transportation systems or hubs (Browne et al. 2016). Nevertheless, it is proved that social distancing measures are important in order to contain an emerging disease (Eubank et al. 2004). Wang (2014) based on daily data from Taipei City in Taiwan found a 50\% decrease in underground ridership during the peak of the 2003 SARS pandemic. Lau (2003), based on Hong Kong, showed that the proportion of people avoiding congested places, including public transport hubs, $\mathrm{s}$ increased significantly only in the initial phase of the SARS epidemic. The control measures based on limiting or constraining human mobility are being considered as important in containing the spread of infectious diseases (Bajardi et al. 2011). The impact of travel restrictions due to an epidemic remained difficult to measure in the past due to mobile phone data limitations. Peak et al. (2018), based on routinely collected mobile phone data during the Ebola epidemic in Sierra Leone revealed a dramatic reduction in human mobility only during a 3-day lockdown, while mobility quickly returned to normal patterns after the restrictions were lifted.

There are two main approaches to studying the issue of public transport from the perspective of the COVID-19 pandemic. On the one hand, scientists investigate the impact of the transport sector on the spread of COVID-19. Jinjarak et al. (2020) find that higher initial mobility negatively impacts the epidemic status, particularly the mortality rate. Majority of studies investigate how the transport sector and the changes in transport mobility affect the COVID-19 pandemic spread in China, the country were the novel coronavirus appeared (Chinazzi et al. 2020; Kraemer et al. 2020). Zheng et al. (2020) indicate that COVID-19 cases imported via transportation are a key factor in the pandemic spread. Linka et al. (2020) suggest that an unconstrained mobility would have significantly accelerated the spread of the COVID-19 pandemic, particularly in Central Europe, Spain and France. According to Muller et al. (2020) and Musselwhite et al. (2020) public transport plays a significant role in the spread of infectious diseases, thus attempts to control the spread of infections via public transportation reduces the infection speed. On the other hand, researchers examine how the COVID-19 pandemic, the accompanying combination of government restrictions and social fears of contracting and spreading COVID-19 when using mass transport modes reduce passenger transport demand and worsen the overall situation in transport. Aloi et al. (2020) investigate the effects of the pandemic lockdown on urban mobility. They show that an overall mobility in the northern city of Santander, Spain have fallen by $76 \%$ and the number of public transport users have dropped by up to $93 \%$.

The medical researchers forecast that subsequent waves of the pandemic may result in new waves of social distancing in the near future (Wu et al. 2020). De Vos (2020) claims that social distancing which reduces direct physical interactions between individuals in order to stop the spread of the virus, has become the new norm in the society. The economic and social effects of the COVID-19 pandemic on public transport does not concern only service performance, financial viability, health risks, social equity, and sustainable mobility but goes much further (Tirachini and Cats 2020).

Our contribution is that by applying Pearson's and Spearman's rank correlation coefficients, factor variance analysis (ANOVA) and the Tukey's honest significance test (Tukey's HSD test) we can investigate the COVID-19 pandemic-driven changes in mobility in public transport in Poland from 
the country and regional (voivodeships) perspective. To our knowledge, there have been no similar studies conducted yet.

The outline of the paper is as follows: the next section presents the aim of the study, research hypotheses and a description of the material and research methods used. The subsequent section sets out the empirical findings and discussion, with the final section offering our conclusions.

\section{Methodology}

The aim of the paper is to assess the changes in mobility in public transport in Poland as a consequence of the development of the COVID-19 pandemic. The expected key factors affecting changes in mobility in public transport during the COVID-19 pandemic are the epidemic status in the country and the stringency of government restriction policy to tackle the coronavirus. It is in line with Warren and Skillman (2020) who indicate that a large decrease in mobility on a global scale has been associated with the outbreak of the COVID-19 threat and specific government directives. In order to achieve the main aim of the study, we build three research hypotheses.

Hypothesis 1. The relationship between the changes in mobility in public transport and new laboratory-confirmed cases of COVID-19 in Poland is negative and significant.

Hypothesis 2. The relationship between the changes in mobility in public transport and the stringency of Polish government's anti-COVID-19 policy is negative and significant.

Hypothesis 3. There is significant difference in changes in mobility in public transport regarding "low", "medium" and "high" stringency of Polish government's anti-COVID-19 policy.

Due to the diverse epidemic status and expected different mobility behaviour in particular provinces of Poland, we verify the hypotheses from the country as well as all 16 voivodeships (provinces) perspective, i.e., Greater Poland, Holy Cross, Kuyavian-Pomeranian, Lesser Poland, Lower Silesian, Lublin, Lubusz, Łódź, Masovian, Opole, Podlaskie, Pomeranian, Silesian, Subcarpathian, Warmian-Masurian, and West Pomeranian. Figure 1 presents the administrative division of Poland into voivodeships.

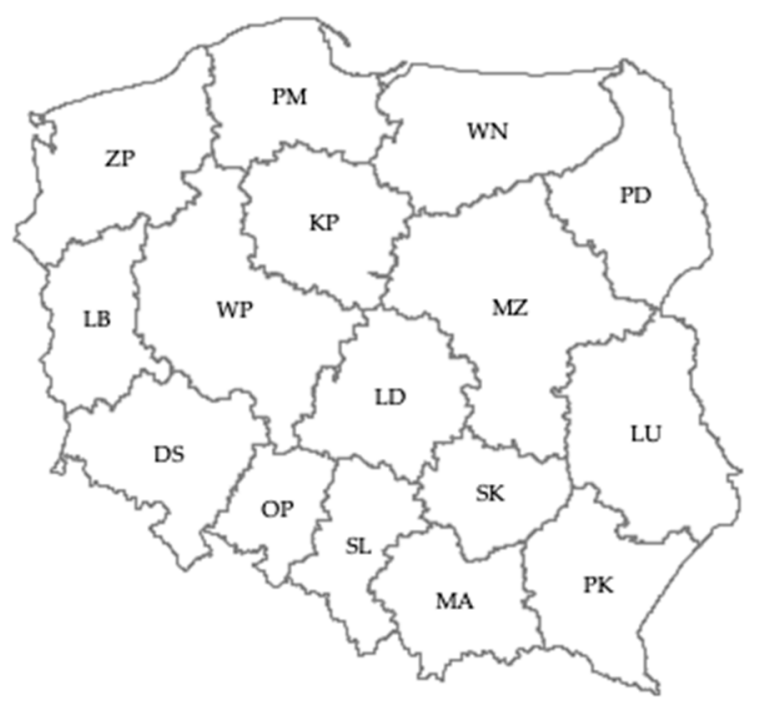

Figure 1. The administrative division of Poland into voivodeships. DS-Lower Silesian; KPKuyavian-Pomeranian; LU—Lublin; LB_Lubusz; LD—Łódź; MA—Lesser Poland; MZ—Masovian; OP-Opole; PK—Subcarpathian; PD—Podlaskie; PM-Pomeranian; SL-Silesian; SK-Holy Cross; WN-Warmian-Masurian; WP-Greater Poland; ZP_West Pomeranian. Source: own elaboration. 
To determine the changes in mobility in public transport we use Google data from COVID-19 Community Mobility Reports on transit stations category developed by Google. Google has developed the reports in order to assess how peoples' movements have changed throughout the pandemic. The reports visualize changes in the number of visits and time spent in certain place categories, such as such retail and recreation, supermarkets and pharmacies, parks, public transport, workplaces and residential, in relation to the baseline period prior to the outbreak of the pandemic. Due to different routines on weekdays and weekends, baseline periods represent a normal value for each day of the week, given as median value over the five-week period from 3rd January to 6th February 2020 (Google 2020; Ritchie 2020). Google highlights the usage of anonymized data provided by applications such as Google Maps. COVID-19 Community Mobility Reports identify six categories of public mobility places (Google 2020): retail and recreation (restaurants, cafes, shopping centres, theme parks, museums, libraries, and movie theatres), grocery and pharmacy (grocery markets, food warehouses, farmers markets, specialty food shops, drug stores, and pharmacies), parks (national parks, public beaches, marinas, dog parks, plazas, and public gardens), transit stations (public transport hubs, including subway, bus and train stations), workplaces, and residential (places of residence). The data on daily new laboratory-confirmed cases of COVID-19 in Poland and 16 voivodeships was collected from the official Twitter account of the Ministry of Health of the Republic of Poland. To measure the stringency of the government response to the outbreak of the COVID-19 pandemic we use data on the Stringency index from the Oxford COVID-19 Government Response Tracker developed by the Blavatnik School of Government (Hale et al. 2020). The index provides a systematic measure of tracking the severity level of government responses to the COVID-19 pandemic in time across more than 150 countries. The Stringency index consists of eight individual government response measures, including: school closing, workplace closing, public events cancellations, restrictions on gathering size, public transport closing, stay-at-home requirements, restrictions on internal movements, restrictions on international travel and public information campaign. The index ranges from 0 to 100 (Hale et al. 2020).

The research covers the period between 2 March and 19 July 2020, i.e., the time since the first laboratory-confirmed COVID-19 case in Poland up to the latest available data (as of 24 July 2020). In order to avoid mismatching different people's mobility routines on weekdays and weekends we convert daily data into weekly averages. In we apply Pearson's and Spearman's rank correlation coefficients and corresponding significance tests to measure the relationship between: changes in mobility in public transport and new laboratory-confirmed cases of COVID-19, and mobility changes in public transport and the Stringency index level changes. Measuring correlation between two or more variables requires knowledge of their joint distribution. As the joint distribution is normal, the Pearson's correlation coefficient is applied. Otherwise, the relationship between variables is calculated based on Spearman's rank correlation coefficient. The joint distribution of analysed variables' normality is determined with Shapiro Wilk test. The Shapiro-Wilk test is the most powerful normality test that can be also applied for small sample size and for all levels of skewness and kurtosis of distributions (Yap and Sim 2011).

Additionally, we supply our study with one factor variance analysis (ANOVA) and the Tukey's honest significance test (Tukey's HSD test) to check whether the stringency of Polish government's anti-COVID-19 policy has significant impact on changes in mobility in public transport both from country and regional perspective. The Stringency index is assumed to be the factor. Based on the stringency index daily data we build qualitative variable which has three levels. The first level-“low", represents low level of Polish government stringency policy, i.e., the stringency index lower than 40. The "medium" level is assigned to all days when the stringency index is in the range between 41 and 70. The "high" level is attributed to all daily periods with severe anti-COVID regulations, i.e., the stringency index higher than 71 . 


\section{Research Results and Discussion}

The rapid increase in laboratory-confirmed COVID-19 cases across the world result in growing international concerns. In line with WHO recommendations, the Polish government began implementing restrictions and limitations aimed at limiting the spread of COVID-19. Table 1 presents an order of events related to the spread of the COVID-19 epidemic in the world and in Poland, as well as Polish government anti-COVID-19 restrictions related directly or indirectly to transportation.

Table 1. The coronavirus pandemic development and the Polish government anti-COVID-19 policy regulations related to transportation-timeline.

\begin{tabular}{|c|c|}
\hline Description & Date \\
\hline \multicolumn{2}{|l|}{ Global perspective } \\
\hline Unpublished Chinese government report on first cases of a novel coronavirus infections. & 17 November 2019 \\
\hline The first confirmed case of a novel coronavirus infection in Wuhan, China. & 8 December 2019 \\
\hline The first confirmed cases of a novel coronavirus infection in Europe, Italy. & 23 January 2020 \\
\hline WHO declares the novel coronavirus outbreak a Public Health Emergency of International Concern. & 30 January 2020 \\
\hline $\begin{array}{l}\text { The International Committee on Taxonomy of Viruses (ICTV) names a novel coronavirus: SARS-CoV-2. } \\
\text { WHO announces an official name for the disease caused by the coronavirus: COVID- } 19 \text {. }\end{array}$ & 11 February 2020 \\
\hline WHO announces that COVID-19 can be officially described as a pandemic. & 11 March 2020 \\
\hline \multicolumn{2}{|l|}{ Poland } \\
\hline The first laboratory-confirmed case of COVID-19, Lubusz voivodeship. & 4 March 2020 \\
\hline Border controls and ban on mass events. & 10 March 2020 \\
\hline The first reported COVID-19 death, Greater Poland. & 12 March 2020 \\
\hline school closing, restrictions on internal movement & 12 March 2020 \\
\hline The government announces an epidemic threat on the territory of Poland & 14 March 2020 \\
\hline Restriction on functioning of selected institutions and workplaces, remote working obligation & 14 March 2020 \\
\hline Suspension of international passenger air and rail connections, restrictions on cross-border movements & 15 March 2020 \\
\hline The government announces epidemic in Poland. & 20 March 2020 \\
\hline $\begin{array}{l}\text { Restrictions on movement except commuting to work, essential matters of everyday life and } \\
\text { volunteering in the fight against COVID-19. }\end{array}$ & 24 March 2020 \\
\hline Maximal number of passengers on public transport (buses, trams, metro) equal half the number of seats. & 24 March 2020 \\
\hline Restrictions on gathering, stay-at-home policy implementation & 31 March 2020 \\
\hline Mandatory nose and mouth covering in public places & 16 April 2020 \\
\hline $\begin{array}{l}\text { The first stage of lifting restrictions related to COVID-19 (possibility of movement for recreational } \\
\text { purposes, easing restrictions in trade and services). }\end{array}$ & 20 April 2020 \\
\hline $\begin{array}{l}\text { The second stage of lifting restrictions related to COVID-19 (opening of shopping centres, hypermarkets } \\
\text { and hotels). }\end{array}$ & 4 May 2020 \\
\hline $\begin{array}{l}\text { The third stage of lifting restrictions related to COVID- } 19 \text { (partial abolition of public transport } \\
\text { restrictions to increase the number of passengers to } 30 \% \text { of all seats and standing places). }\end{array}$ & 18 May 2020 \\
\hline $\begin{array}{l}\text { The fourth stage (first part) of lifting restrictions related to COVID-19 (lifting the limits of people in } \\
\text { shops, post offices, restaurants, and places of religious worship). }\end{array}$ & 30 May 2020 \\
\hline $\begin{array}{l}\text { Partial abolition of public transport restrictions to increase the number of passengers to } 100 \% \text { of seats or } \\
50 \% \text { of all seats and standing places, resumption of internal passenger flights. }\end{array}$ & 1 June 2020 \\
\hline $\begin{array}{l}\text { The fourth stage (second part) of lifting restrictions related to COVID-19 (full opening of hotels, } \\
\text { swimming pools, fitness clubs, and places of culture, enabling gatherings up to } 150 \text { persons). }\end{array}$ & 6 June 2020 \\
\hline Lifting restrictions on traffic at borders & 13 June 2020 \\
\hline Resumption of international passenger flights. & 16 June 2020 \\
\hline
\end{tabular}

Compared to other European Union (EU) Member States, Poland is one of the last countries to experience the outbreak of the COVID-19. By 19 July 2020 more than one per mile of Poles have experienced the coronavirus. At the same time the number of deaths related to COVID-19 has 
reached 1623, resulting in a $4 \%$ coronavirus mortality rate. Epidemic status in Poland is diverse across 16 voivodeships, as Figure 2 depicts.

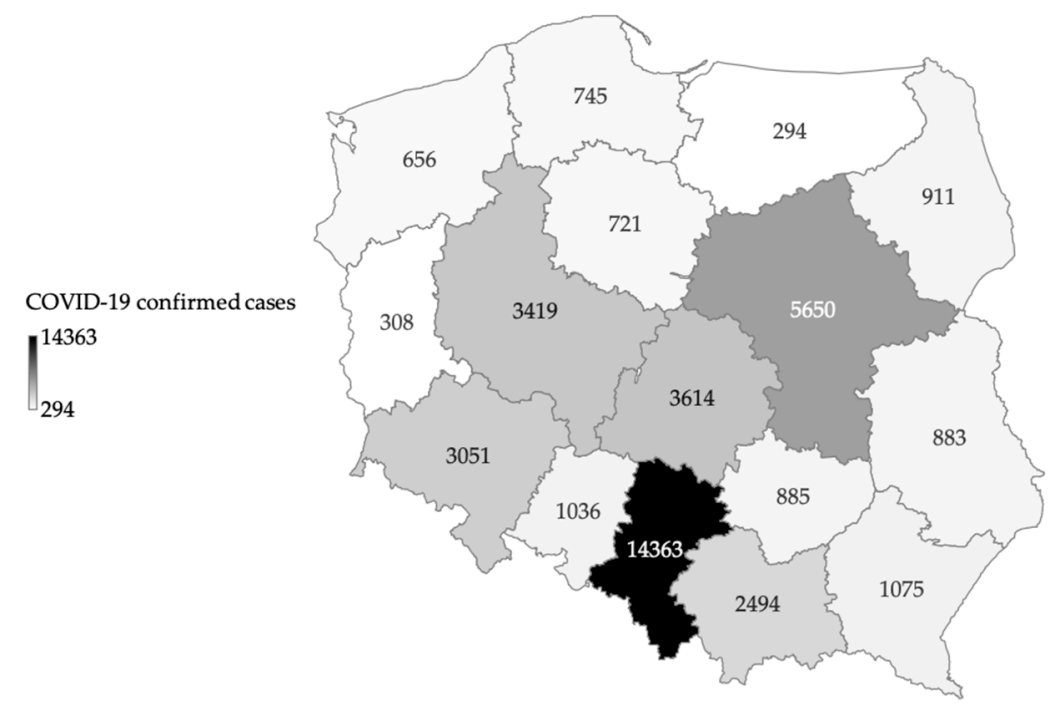

Figure 2. Laboratory-confirmed COVID-19 cases in Poland by voivodeship, by 19 July 2020. Source: own elaboration based on Ministry of Health of the Ministry of Health of the Republic of Poland data (2020).

The COVID-19 crisis has hit all forms of transport, including both public and private sectors, nationally and internationally. Global road transport, by the end of March 2020, has decreased more than $50 \%$ compared to the same period in 2019 . The flight activity was almost $75 \%$ lower by mid-April 2020, compared to the same period in 2019 (IEA 2020). A combination of the government restrictions and social fears of contracting and spreading COVID-19 when using mass transport modes has caused the reduction in passenger transport demand. Figure 3 presents the monthly numbers of passengers carried by public transport in Poland from January to June 2020. We observe a substantial decrease in passenger transport in Poland since the COVID-19 pandemic outbreak in March 2020. By the end of April the total number of passenger in public transport had dropped by $77 \%$ in comparison to January 2020. Due to the government restrictions implementation, the air passenger transport had become least used. As a consequence of subsequent stages of restriction easing in June 2020, nearly 21 million passengers in Poland were carried by public transport, 38.6 percent more than in May (Figure 3).

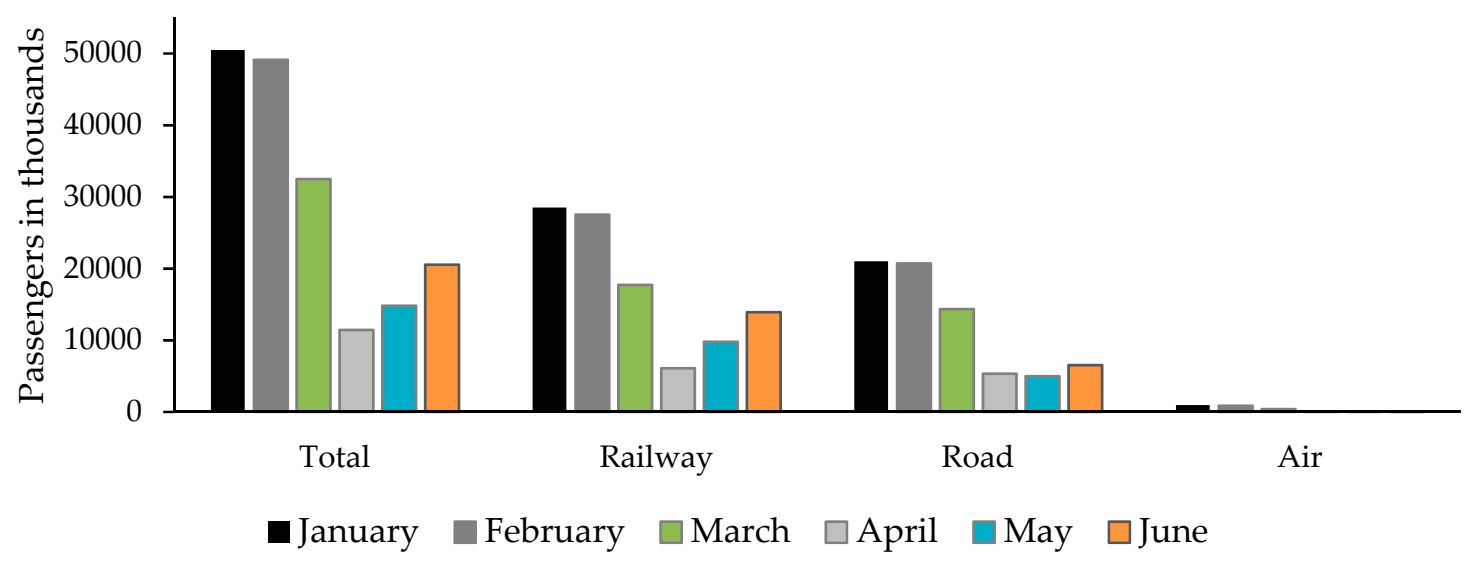

Figure 3. Passenger transport in Poland from January to June 2020 by means of transport, in 1000 persons. Source: own elaboration based on Statista (2020). 
The mobility is likely to be affected by the epidemic status in the country and the stringency of government restriction policy to tackle the coronavirus. Figure 4 depicts the average weekly changes in mobility in public transport and the number of average weekly COVID-19 new cases. Google COVID-19 Community Mobility data shows that peoples' movements have changed dramatically throughout the pandemic. According to Troko et al. (2011) every means of transport can be treated as a place where it has become difficult to avoid interpersonal contact. Therefore, people should avoid public transport in order not to be infected.

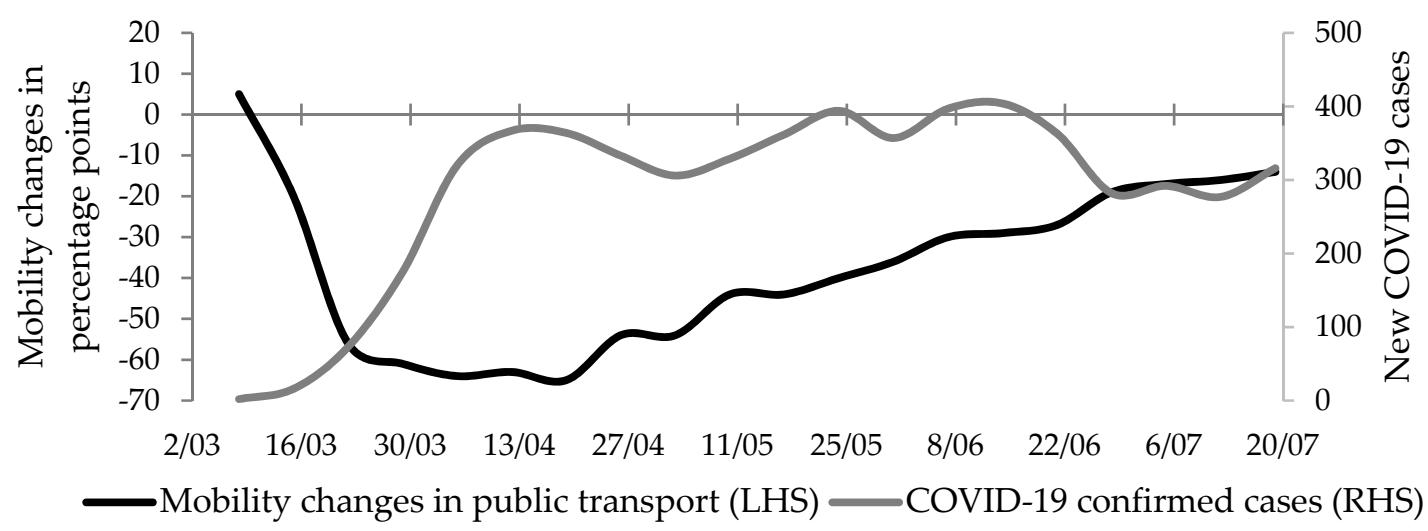

Figure 4. Mobility changes in public transport and new laboratory-confirmed cases of COVID-19 in Poland from 2 March to 19 July 2020. Source: own elaboration based on data from Google COVID-19 Community Mobility Reports (Google 2020) and Ministry of Health of the Ministry of Health of the Republic of Poland (2020).

Figure 4 indicates that the increase in the number of new COVID-19 cases was associated with the sharp decline in the mobility of people in public transport, particularly till mid-April 2020. However, since the beginning of May, a large increase in human mobility was observed, despite the constantly high number of new laboratory-confirmed cases of COVID-19. It may suggest that the strength of the relationship between mobility in public transport and the epidemic status has decreased with the development of the COVID-19 pandemic in Poland. Table 2 shows estimated correlation coefficients between changes in mobility in public transport and the number of new confirmed cases across the country and in each of the 16 voivodeships. The normality of joint distribution of analysed variables is tested with the Shapiro Wilk test. When estimated p-values are lower than 0.05 level of significance, the null hypothesis of normality is rejected. When the joint distribution is normal, the Pearson's correlation coefficient is applied. Otherwise, we use the Spearman's rank correlation coefficient.

The results presented in Table 2 indicate the existence of negative relationship between mobility changes in public transport and new laboratory-confirmed cases of COVID-19, both in Poland and in the vast majority of voivodeships. However, the results are significant, at 0.05 significance level, only for Kuyavian-Pomeranian, Lower Silesian, Masovian, Pomeranian and West Pomeranian voivodeships, for which the research results are consistent with the first hypothesis presented in the paper. The estimated Spearman's rank correlation coefficient for Poland equals -0.29 , while at the regional level the correlation coefficients varies substantially from 0.10 to -0.69 . The strongest negative relationship is observed for Lower Silesian, Masovian and West Pomeranian. The obtained results indicate regional differences in the strength and significance of the relationship between changes in mobility in public transport and new confirmed cases. Voivodeships that have a significant, strong and negative correlation are those in which increasing number of new COVID-19 cases coincide with stricter government restrictions, when human mobility in Poland decreased the most. What may be surprising the relationship is insignificant but positive for Silesian, the province most affected by the coronavirus pandemic. It may be due to the fact that in this voivodeship a large number of new COVID-19 cases occurred at the time of easing the restrictions. 
Table 2. The relationship between mobility changes in public transport and new laboratory-confirmed cases of COVID-19 in Poland.

\begin{tabular}{|c|c|c|c|c|}
\hline Variable & Shapiro-Wilk Test Statistic & $p$-Value & Correlation Coefficient & $p$-Value \\
\hline POLAND & 0.87 & 0.01 & $-0.29^{S}$ & 0.21 \\
\hline Greater Poland & 0.97 & 0.76 & $-0.36^{\mathrm{P}}$ & 0.15 \\
\hline Holy Cross & 0.98 & 0.91 & $-0.11^{\mathrm{P}}$ & 0.64 \\
\hline Kuyavian-Pomeranian & 0.75 & $<0.001$ & $-0.50^{\mathrm{S}}$ & 0.02 \\
\hline Lesser Poland & 0.77 & $<0.001$ & $-0.14^{\mathrm{S}}$ & 0.55 \\
\hline Lower Silesian & 0.97 & 0.84 & $-0.76^{\mathrm{P}}$ & $<0.001$ \\
\hline Lublin & 0.89 & 0.03 & $-0.24^{\mathrm{S}}$ & 0.30 \\
\hline Lubusz & 0.59 & $<0.001$ & $-0.10^{\mathrm{S}}$ & 0.66 \\
\hline Łódź & 0.91 & 0.05 & $0.10^{\mathrm{P}}$ & 0.67 \\
\hline Masovian & 0.95 & 0.34 & $-0.58^{\mathrm{P}}$ & 0.01 \\
\hline Opole & 0.98 & 0.94 & $-0.39^{\mathrm{P}}$ & 0.09 \\
\hline Podlaskie & 0.97 & 0.85 & $-0.22^{\mathrm{P}}$ & 0.34 \\
\hline Pomeranian & 0.80 & $<0.001$ & $-0.45^{\mathrm{S}}$ & 0.04 \\
\hline Silesian & 0.92 & 0.08 & $0.10^{\mathrm{P}}$ & 0.67 \\
\hline Subcarpathian & 0.81 & 0.01 & $0.12^{\mathrm{S}}$ & 0.61 \\
\hline Warmian-Masurian & 0.96 & 0.58 & $-0.30^{\mathrm{P}}$ & 0.20 \\
\hline West Pomeranian & 0,97 & 0.72 & $-0.69^{\mathrm{P}}$ & $<0.001$ \\
\hline
\end{tabular}

Figure 5 shows that with the introduction of subsequent government restrictions, a sharp decline in the mobility of people in public transport was observed until mid-April 2020. It might indicate that the forced lockdown has proven to be effective in reducing interpersonal contacts in order to halt the pandemic development. Starting from the second half of April 2020, an increase in mobility in public transport is visible, which can be explained by the fact that the Polish society has learned to function more effectively despite the social distancing regulations. Strong easing of government regulations resulted in a decrease in the Stringency index level in Poland from the beginning of June 2020. In the same period further increase in mobility in public transport is visible.

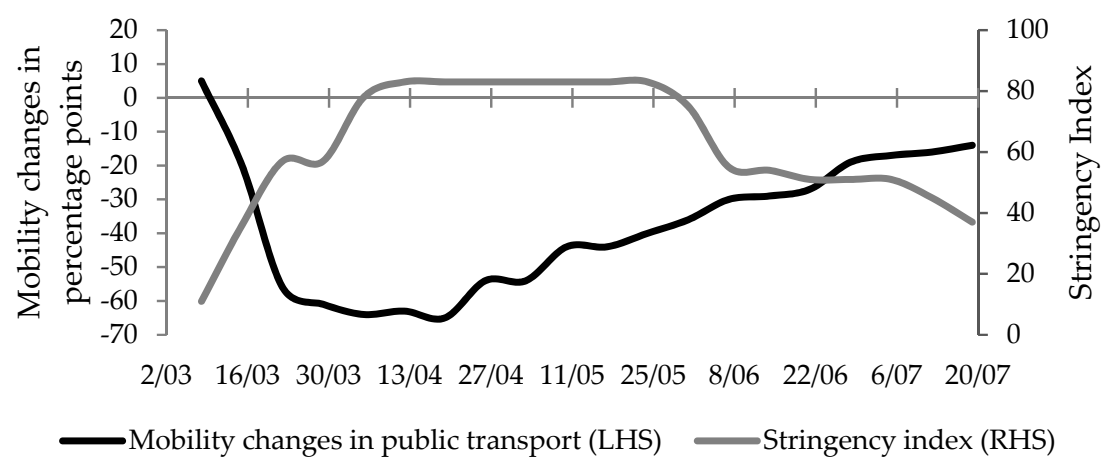

Figure 5. Changes in mobility in public transport and the Stringency index level changes in Poland from 2 March to 19 July 2020. Source: own elaboration based on data from Google COVID-19 Community Mobility Reports (Google 2020) and the Oxford COVID-19 Government Response Tracker (Hale et al. 2020). 
Table 3 presents the results of Shapiro Wilk test and estimated correlation coefficients between changes in mobility in public transport and stringency of government restriction policy to tackle the coronavirus. The study reveals strong, negative and significant relationship both for Poland and all 16 voivodeships. It is consistent with the second hypothesis. It implies that the higher is the severity level of government responses to the COVID-19 pandemic, the lower is the mobility in public transport. The estimated Spearman's rank correlation coefficient for Poland equals -0.84 . Correlation coefficients range from -0.72 to -0.86 across voivodeships.

Table 3. The relationship between changes in mobility in public transport and the Stringency index level changes in Poland.

\begin{tabular}{|c|c|c|c|c|}
\hline Variable & Shapiro-Wilk Test Statistic & $p$-Value & Correlation Coefficient & $p$-Value \\
\hline POLAND & 0.89 & 0.02 & $-0.84^{\mathrm{S}}$ & $<0.001$ \\
\hline Greater Poland & 0.91 & 0.06 & $-0.83^{\mathrm{P}}$ & $<0.001$ \\
\hline Holy Cross & 0.88 & 0.02 & $-0.84^{\mathrm{S}}$ & $<0.001$ \\
\hline Kuyavian-Pomeranian & 0.92 & 0.08 & $-0.74^{\mathrm{P}}$ & $<0.001$ \\
\hline Lesser Poland & 0.91 & 0.08 & $-0.85^{\mathrm{P}}$ & $<0.001$ \\
\hline Lower Silesian & 0.90 & 0.04 & $-0.86^{\mathrm{S}}$ & $<0.001$ \\
\hline Lublin & 0.89 & 0.03 & $-0.85^{\mathrm{S}}$ & $<0.001$ \\
\hline Lubusz & 0.91 & 0.07 & $-0.78^{\mathrm{P}}$ & $<0.001$ \\
\hline Łódź & 0.89 & 0.03 & $-0.84^{\mathrm{S}}$ & $<0.001$ \\
\hline Masovian & 0.92 & 0.11 & $-0.85^{\mathrm{P}}$ & $<0.001$ \\
\hline Opole & 0.92 & 0.10 & $-0.79^{\mathrm{P}}$ & $<0.001$ \\
\hline Podlaskie & 0.87 & 0.01 & $-0.83^{S}$ & $<0.001$ \\
\hline Pomeranian & 0.90 & 0.04 & $-0.82^{S}$ & $<0.001$ \\
\hline Silesian & 0.87 & 0.01 & $-0.82^{\mathrm{S}}$ & $<0.001$ \\
\hline Subcarpathian & 0.87 & 0.01 & $-0.84^{\mathrm{S}}$ & $<0.001$ \\
\hline Warmian-Masurian & 0.91 & 0.07 & $-0.72^{\mathrm{P}}$ & $<0.001$ \\
\hline West Pomeranian & 0.92 & 0.10 & $-0.75^{\mathrm{P}}$ & $<0.001$ \\
\hline
\end{tabular}

The obtained results presented in Tables 2 and 3 suggest that the relationship between the changes in mobility in public transport and the stringency of anti-COVID-19 government restriction policy is stronger than the relationship between the mobility and new laboratory-confirmed cases of COVID-19. It suggests that government restrictions and ongoing pandemic information campaigns have a greater impact on human mobility rather than information about new confirmed cases. It is in line with the results of Engle et al. (2020) who show that government stay-at-home restrictions induce a greater mobility decrease than a rise of local infection rate.

As the above presented results show, that government stringency policy is a key factor affecting mobility changes during the COVID-19 pandemic. We apply one factor variance analysis (ANOVA) and the Tukey's honest significance test (Tukey's HSD test) in order to analyse the patterns of mobility in public transport both from country and regional perspective. The results of the ANOVA test are presented in Table 4. Stringency of Polish government's anti-COVID-19 policy is assumed to be the factor while the changes in mobility in public transport are considered as a dependent variable. 
Table 4. One factor analysis of variance (ANOVA) between the Stringency index levels and changes in mobility in public transport.

\begin{tabular}{ccc}
\hline Region & F Statistics & $p$-Value \\
\hline POLAND & 84.72 & $<0.001$ \\
\hline Greater Poland & 84.18 & $<0.001$ \\
\hline Holy Cross & 65.19 & $<0.001$ \\
\hline Kuyavian-Pomeranian & 62.87 & $<0.001$ \\
\hline Lesser Poland & 105.2 & $<0.001$ \\
\hline Lower Silesian & 92.78 & $<0.001$ \\
\hline Lublin & 69.47 & $<0.001$ \\
\hline Lubusz & 72.01 & $<0.001$ \\
\hline Łódź & 64.88 & $<0.001$ \\
\hline Masovian & 92.88 & $<0.001$ \\
\hline Opole & 70.08 & $<0.001$ \\
\hline Podlaskie & 61.07 & $<0.001$ \\
\hline Pomeranian & 95.07 & $<0.001$ \\
\hline Silesian & 59.26 & $<0.001$ \\
\hline Subcarpathian & 76.20 & $<0.001$ \\
\hline Warmian-Masurian & 60.56 & $<0.001$ \\
\hline West Pomeranian & 68.81 & $<0.001$
\end{tabular}

Source: own calculations using R based on data from Google COVID-19 Community Mobility Reports (Google 2020) and the Oxford COVID-19 Government Response Tracker (Hale et al. 2020).

The result presented in Table 4 implies the significant relationship between the stringency of Polish government's anti-COVID-19 policy and changes in mobility in public transport both in Poland and all voivodeships at the $1 \%$ level of significance. The results indicate that there is a significant difference in mean changes in mobility between at least two levels of stringency factor. In order to analyse the pattern of difference between means we test all pairwise comparisons among means applying Tukey's HSD test. The test results are presented in Table A1 in Appendix A. Tukey's HSD test results show that there is a significant difference between the changes in mobility in public transport at both "high" and "medium" stringency levels in comparison to "low" level, and at "high" in comparison to "medium" level at 1\% significance level in Poland and all analysed voivodeships. Figure 6 depicts the mean changes in mobility in public transport in Poland depending on three stringency factor levels, i.e., "low", "medium" and "high".

Figure 6 indicates the existence of significant differences in the average changes in mobility in public transport in Poland at all three levels of stringency factor, which has been confirmed by Tukey's HSD test (Table A1). From the country's perspective we observe a decrease of average mobility in public transport in entire research period. During the soft Polish government's anti-COVID-19 policy periods, the average decrease in mobility in public transport is rather minor. As the anti-COVID-19 policy becomes more stringent, the mean level of population mobility in public transport substantially declines. Figure $\mathrm{A} 3 \mathrm{a}, \mathrm{b}$ in the appendix show the mean mobility changes in public transport in all 16 voivodeships at three stringency factor levels. Figure A3 indicates not only the significant differences in mean changes in mobility in public transport at three levels of stringency factor but also the difference in the magnitude of mobility changes among Polish voivodeships. Figure 7 displaying changes in mobility in public transport dependent on the level of the stringency of anti-COVID-19 policy implies regionally differentiated people's appearance in public transportation system and hubs. 


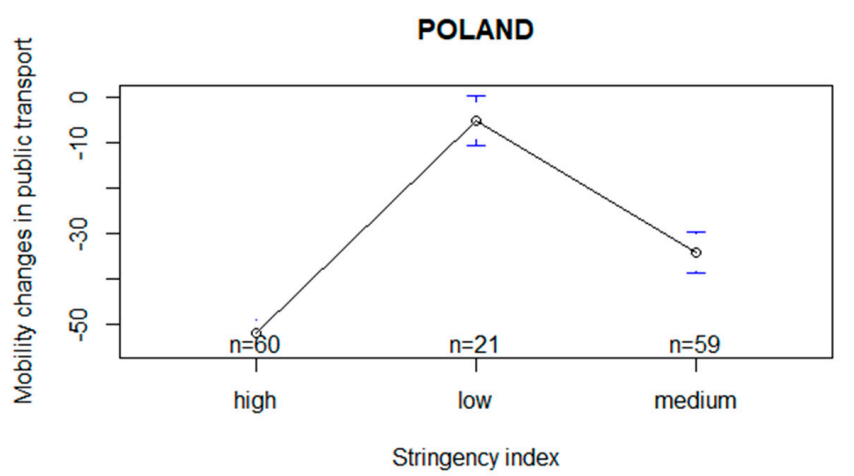

Figure 6. The mean changes in mobility in public transport at three levels of the stringency of Polish government's anti-COVID-19 policy in Poland from 2 March to 19 July 2020. Source: own calculations using R based on data from Google COVID-19 Community Mobility Reports (Google 2020) and the Oxford COVID-19 Government Response Tracker (Hale et al. 2020).

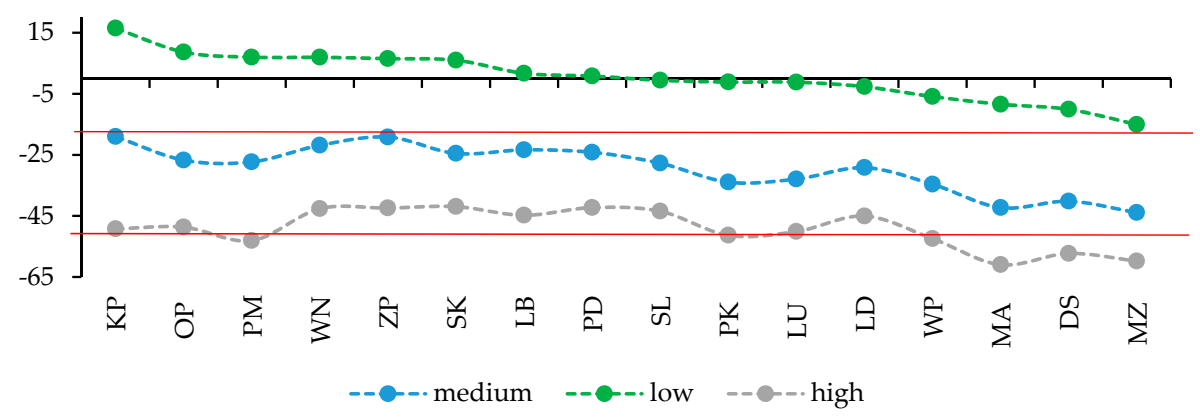

Figure 7. The mean changes in mobility in public transport at three levels of the stringency of Polish government's anti-COVID-19 policy in 16 voivodeships from 2 March to 19 July 2020. DS-Lower Silesian; KP-Kuyavian-Pomeranian; LU—Lublin; LB—Lubusz; LD—Eódź; MA—Lesser Poland; MZ-Masovian; OP—Opole; PK—Subcarpathian; PD—Podlaskie; PM-Pomeranian; SL—Silesian; SK-Holy Cross; WN-Warmian-Masurian; WP-Greater Poland; ZP_West Pomeranian. Source: own calculations using R based on data from Google COVID-19 Community Mobility Reports (Google 2020) and the Oxford COVID-19 Government Response Tracker (Hale et al. 2020).

Figure 7 shows that in the "low" level of stringency policy the largest regional diversity is observed. Surprisingly, only half of the voivodeships experience a decline in average mobility in public transport. Masovian (MZ) represents the highest drop in mobility $(-15 \%)$ while in Kuyavian-Pomeranian (KP) a reverse trend is visible $(+16 \%)$. As far as "medium" and "high" stringency levels are concerned, all sixteen voivodeships experience a substantial decrease in mobility in public transport. However, the magnitude of changes in mobility varies across Polish regions. It is worth adding that during the most severe anti-COVID-19 policy period, in as many as seven voivodeships, the mobility decreased by more than half compared to the baseline period. Moreover, the highest mobility decrease, regardless the stringency level, is observed in Masovian (MZ), Lower Silesian (DS) and Lesser Poland (MA), while Kuyavian-Pomeranian (KP), West Pomeranian (ZP) and Warmian-Masurian (WN) are characterised by the lowest decline in people's appearance in public transportation system and hubs.

Our research results do not correspond with Badr et al. (2020), who reveal the strong correlation between mobility patterns and decreasing number of newCOVID-19 cases. There are certainly other drivers/factors explaining voivodeship-specific relationship between changes in mobility in public transport and epidemic status. It may be population density (Oztig and Askin 2020), initial mobility structure (Galeazzi et al. 2020), personal income (Coven and Gupta 2020; Almagro and Orane-Hutchinson 2020) or diverse perception of the coronavirus pandemic as a consequence of governmental information campaign (Yuksel et al. 2020). However, they were not our subject matter. The results are in line with Pullano et al. (2020) who, based on France, indicate that the pandemic lockdown was very effective in decreasing people 
mobility. Pepe et al. (2020) observe a substantial human mobility reduction in Italy following the national lockdown. Similar results are also obtained a by Queiroz et al. (2020) and Bonaccorsi et al. (2020) who, based on regional analysis, observe the reduction in the circulation of people in most neighbourhoods after government social distancing policies implementation. Moreover, our research results correspond to the studies which focus on the impact of previous epidemics, particularly SARS and Ebola, on population changes in mobility (Wang 2014; Lau 2003; Peak et al. 2018). However, the question remains whether the restrictions aimed at limiting human mobility have a significant effect on the reduction in new COVID-19 cases (Schlosser et al. 2020; Yilmazkuday 2020; Askitas et al. 2020). Our study reveals the regional diversity in the magnitude of mobility changes in public transport depending on the level of severity of the government anti-COVID-19 policy. Explaining the drivers of above mentioned specific, regional relationship raises some challenges for the future research. The literature provides some factors that affect human mobility patterns, including population density (Oztig and Askin 2020), initial mobility structure (Galeazzi et al. 2020), personal income (Coven and Gupta 2020; Almagro and Orane-Hutchinson 2020) or diverse perception of the coronavirus pandemic as a consequence of governmental information campaign (Yuksel et al. 2020).

\section{Conclusions}

Poland is one of the last European Union countries to have experienced the outbreak of COVID-19 pandemic. The epidemic status in Poland is relatively mild. The Polish government restrictions severity and stringency are comparable to those of the other countries affected by the coronavirus. A combination of government lockdown and social fears of contracting and spreading COVID-19 has caused a substantial reduction in passengers' public transport demand in Poland.

From the country as well as voivodeship perspective, the study confirms the statistically significant negative relationship between changes in mobility in public transport and the stringency level of Polish government anti-COVID-19 policy. It might indicate that the forced lockdown to contain the development of the COVID-19 pandemic has effectively contributed to social distancing in public transport in Poland. Moreover, based on ANOVA and Tukey's HSD test we indicate that there are significant differences when it comes to the changes in mobility in public transport depending on the level of stringency of anti-COVID-19 regulation policy both in Poland and all analysed voivodeships. Furthermore, a substantial regional differentiation is visible regardless the stringency policy level. The highest mobility decrease is observed in Masovian, Lower Silesian and Lesser Poland, while Kuyavian-Pomeranian, West Pomeranian and Warmian-Masurian are characterised by the lowest decline in people's appearance in public transport.

However, the significant negative relationship between changes in mobility in public transport and the epidemic status in Poland is not observed. Due to the diverse numbers of laboratory-confirmed COVID-19 cases and expected different mobility behaviour in individual regions of Poland, the assessed relationships vary substantially across voivodeships. The results are significant only for Kuyavian-Pomeranian, Lower Silesian, Masovian, Pomeranian and West Pomeranian voivodeships. What can be considered surprising, the relationship is insignificant but positive for Silesian, the province most affected by the COVID-19 pandemic.

Explaining the drivers of voivodeship-specific relationship between changes in mobility in public transport and the level of severity of the government anti-COVID-19 policy, in particular population density, initial mobility structure, personal income and people's novel coronavirus pandemic perception pose a challenge for the future research.

Author Contributions: Conceptualization: M.W., K.C.; methodology: M.W., K.C.; validation M.W., K.C.; formal analysis K.C., M.W., Ł.G.; writing-original draft preparation: M.W., K.C., Ł.G.; writing-review and editing: M.W., K.C., Ł.G.; supervision: M.W., K.C.; project administration: K.C., M.W. All authors have read and agreed to the published version of the manuscript.

Funding: This research received no external funding.

Conflicts of Interest: The authors declare no conflict of interest. 
Appendix A

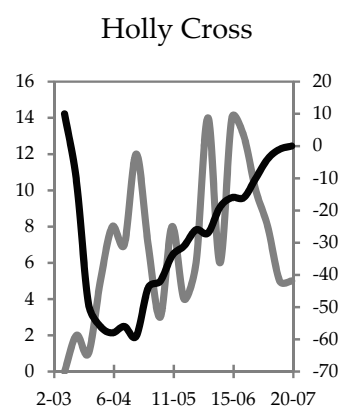

Lower Silesian

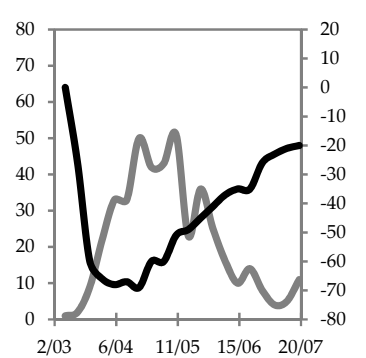

Masovian

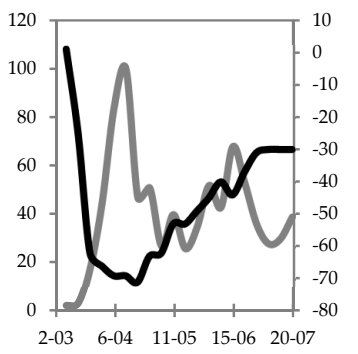

Silesian

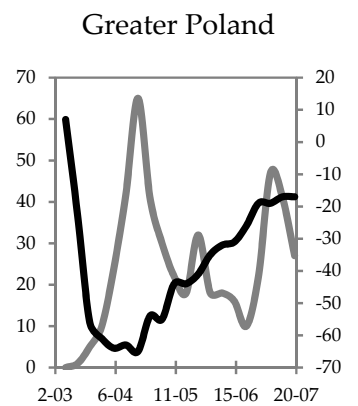

Lublin

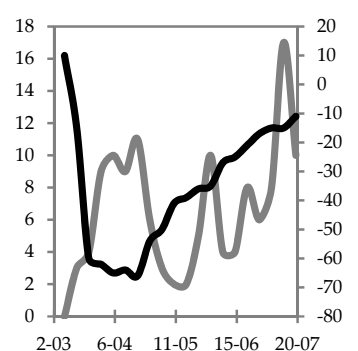

Opole

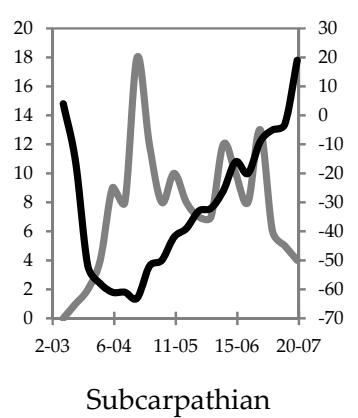

Kuyavian-Pomeranian

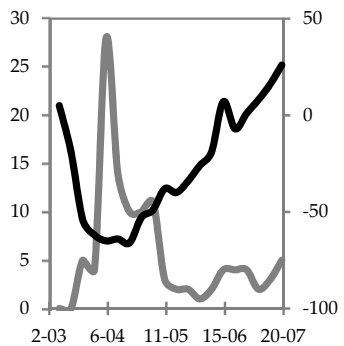

Lubusz

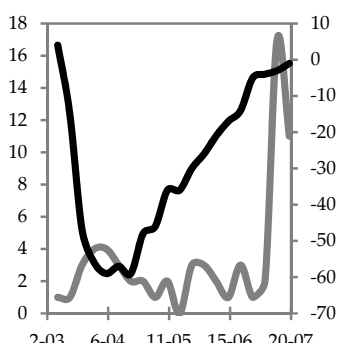

Podlaskie

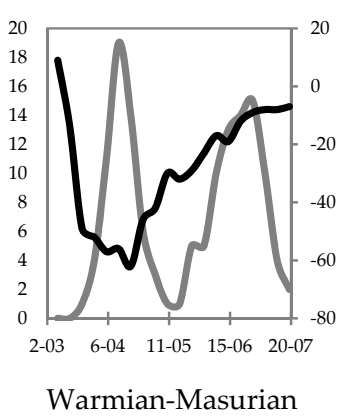

Lesser Poland

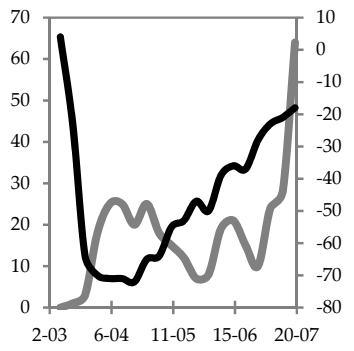

Łódź

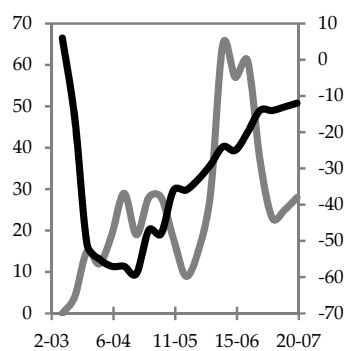

Pomeranian

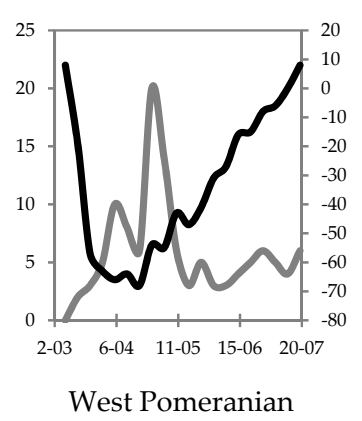

Figure A1. Cont. 

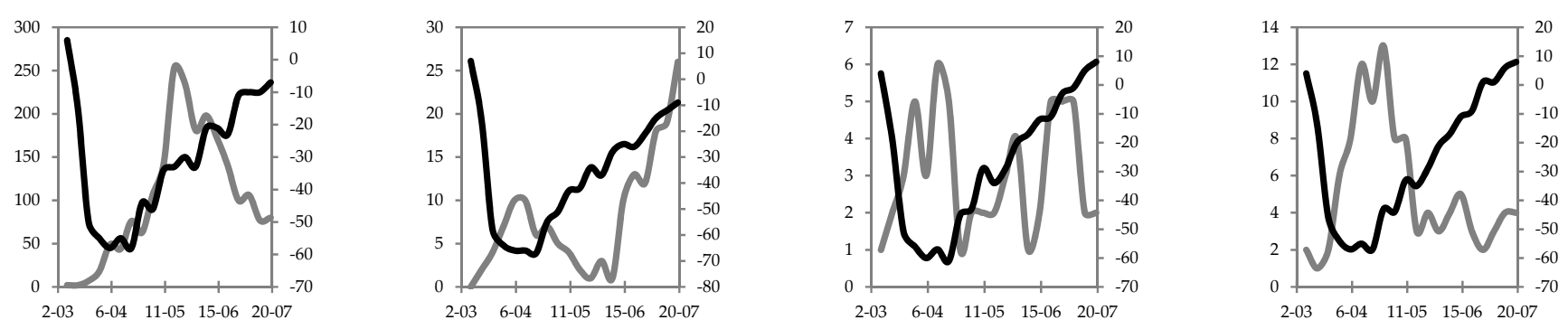

—COVID-19 confirmed cases (LHS - gray line) —Mobility changes in public transport (RHS - black line)

Figure A1. Changes in mobility in public transport and new COVID-19 laboratory-confirmed cases in Poland by voivodeship from 2 March to 19 July 2020 . Source: own elaboration based on data from Google COVID-19 Community Mobility Reports (Google 2020) and Ministry of Health of the Ministry of Health of the Republic of Poland (2020). 


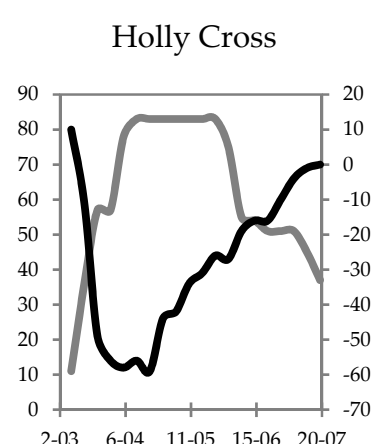

Lower Silesian

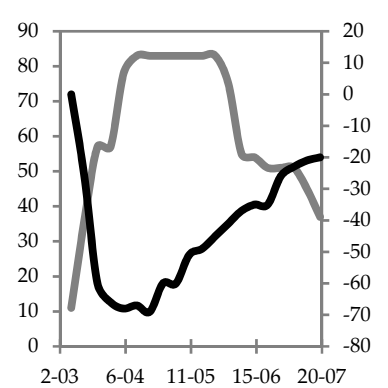

Masovian

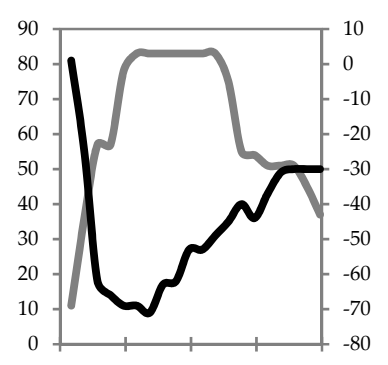

$\begin{array}{lllll}2-03 & 6-04 & 11-05 & 15-06 & 20-07\end{array}$

Silesian
Greater Poland

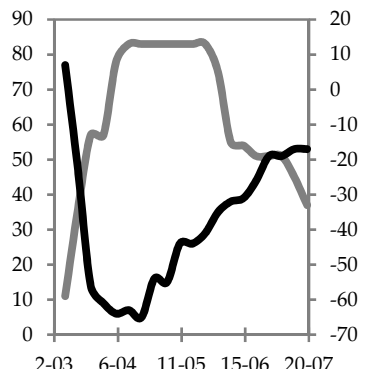

Lublin

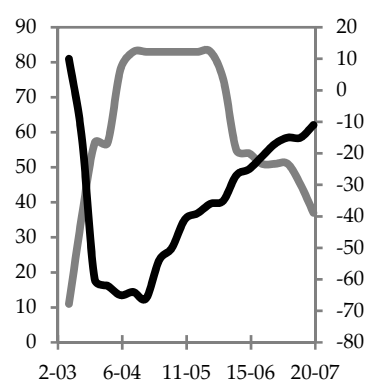

Opole

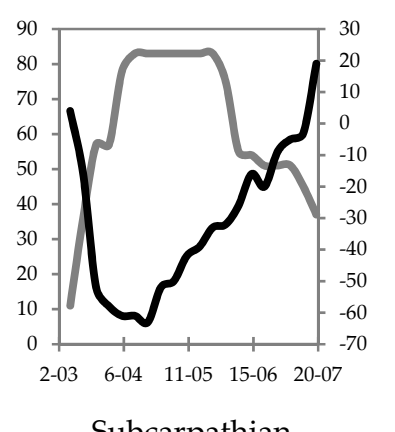

Lesser Poland

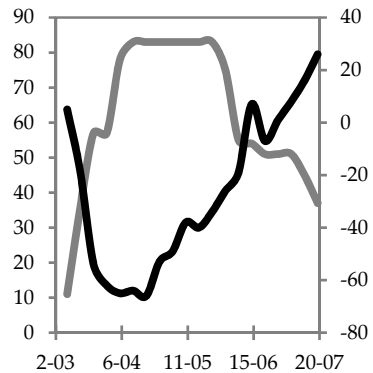

Lubusz

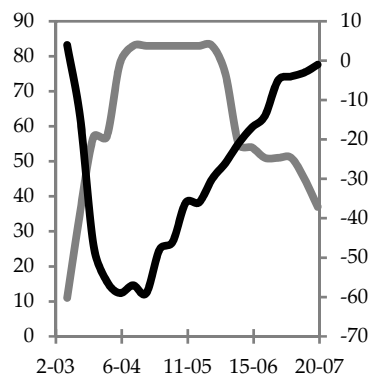

Podlaskie

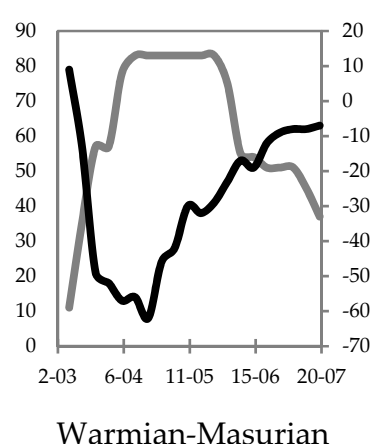

Warmian-Masurian

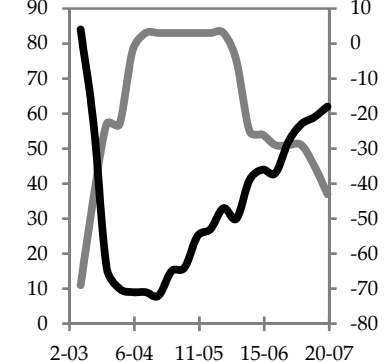

Łódź

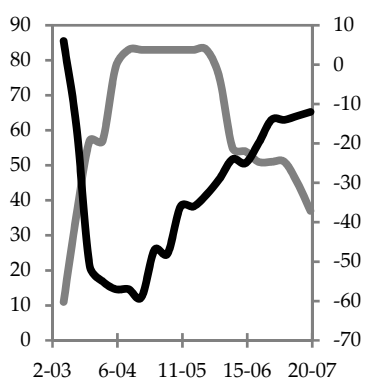

Pomeranian

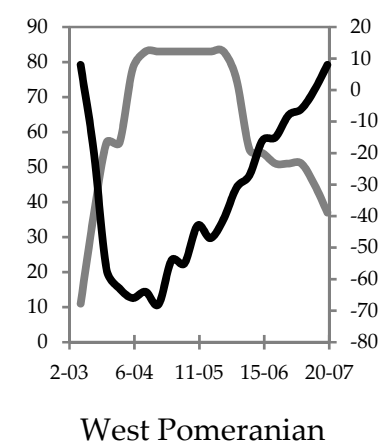

Figure A2. Cont. 

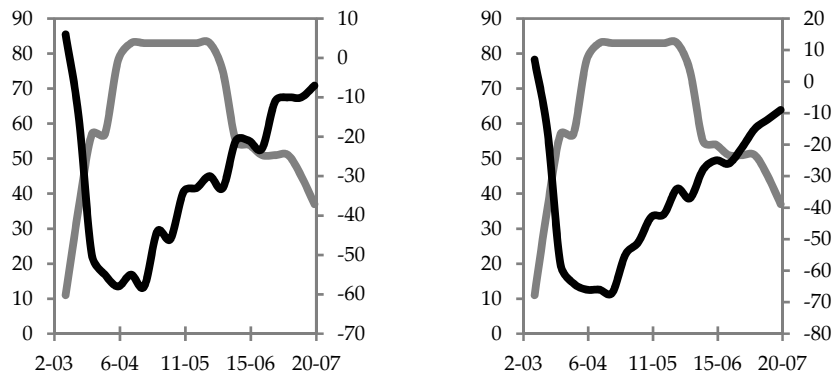

- Stringency index (LHS - gray line)
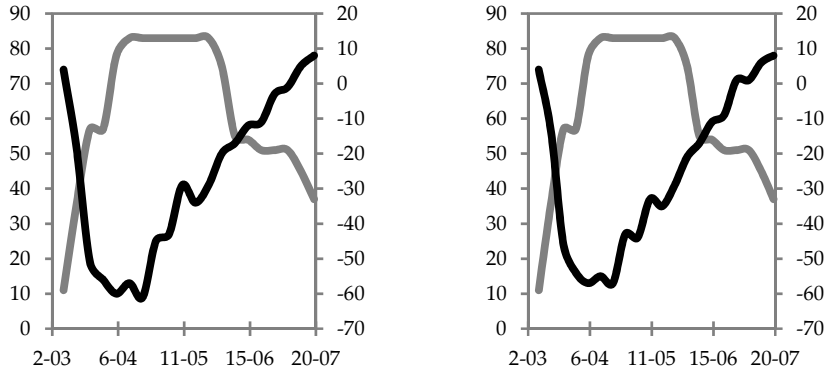

Figure A2. Changes in mobility in public transport and the Stringency index level changes in Poland by voivodeship from 2 March to 19 July 2020 . Source: own elaboration based on data from Google COVID-19 Community Mobility Reports (Google 2020) and the Oxford COVID-19 Government Response Tracker (Hale et al. 2020). 
Table A1. Tukey's honest significance test (Tukey's HSD test).

\begin{tabular}{|c|c|c|c|c|}
\hline \multirow{2}{*}{ Region } & \multirow{2}{*}{ Stringency Policy Level } & \multirow{2}{*}{$\begin{array}{l}\text { Average Value of Changes in } \\
\text { Mobility in Public Transport }\end{array}$} & \multicolumn{2}{|c|}{ Tukey's HSD Test } \\
\hline & & & Difference & $p$-Value \\
\hline \multirow{3}{*}{ POLAND } & low & -5.24 & low-medium & $<0.001$ \\
\hline & medium & -34.32 & low-high & $<0.001$ \\
\hline & high & -52.02 & medium-high & $<0.001$ \\
\hline \multirow{3}{*}{ Greater Poland } & low & -5.90 & low-medium & $<0.001$ \\
\hline & medium & -34.63 & low-high & $<0.001$ \\
\hline & high & -52.45 & medium-high & $<0.001$ \\
\hline \multirow{3}{*}{ Holy Cross } & low & 6.00 & low-medium & $<0.001$ \\
\hline & medium & -24.53 & low-high & $<0.001$ \\
\hline & high & -41.95 & medium-high & $<0.001$ \\
\hline \multirow{3}{*}{ Kuyavian-Pomeranian } & low & 16.48 & low-medium & $<0.001$ \\
\hline & medium & -19.02 & low-high & $<0.001$ \\
\hline & high & -49.25 & medium-high & $<0.001$ \\
\hline \multirow{3}{*}{ Lesser Poland } & low & -8.43 & low-medium & $<0.001$ \\
\hline & medium & -42.29 & low-high & $<0.001$ \\
\hline & high & -60.97 & medium-high & $<0.001$ \\
\hline \multirow{3}{*}{ Lower Silesian } & low & -10.10 & low-medium & $<0.001$ \\
\hline & medium & -40.20 & low-high & $<0.001$ \\
\hline & high & -57.30 & medium-high & $<0.001$ \\
\hline \multirow{3}{*}{ Lublin } & low & -1.19 & low-medium & $<0.001$ \\
\hline & medium & -32.92 & low-high & $<0.001$ \\
\hline & high & -50.13 & medium-high & $<0.001$ \\
\hline \multirow{3}{*}{ Lubusz } & low & 1.71 & low-medium & $<0.001$ \\
\hline & medium & -23.37 & low-high & $<0.001$ \\
\hline & high & -44.78 & medium-high & $<0.001$ \\
\hline \multirow{3}{*}{ Łódź } & low & -2.67 & low-medium & $<0.001$ \\
\hline & medium & -29.20 & low-high & $<0.001$ \\
\hline & high & -45.05 & medium-high & $<0.001$ \\
\hline \multirow{3}{*}{ Masovian } & low & -15.05 & low-medium & $<0.001$ \\
\hline & medium & -43.92 & low-high & $<0.001$ \\
\hline & high & -59.78 & medium-high & $<0.001$ \\
\hline \multirow{3}{*}{ Opole } & low & 8.67 & low-medium & $<0.001$ \\
\hline & medium & -26.71 & low-high & $<0.001$ \\
\hline & high & -48.68 & medium-high & $<0.001$ \\
\hline \multirow{3}{*}{ Podlaskie } & low & 0.81 & low-medium & $<0.001$ \\
\hline & medium & -24.17 & low-high & $<0.001$ \\
\hline & high & -42.28 & medium-high & $<0.001$ \\
\hline \multirow{3}{*}{ Pomeranian } & low & 7.00 & low-medium & $<0.001$ \\
\hline & medium & -27.31 & low-high & $<0.001$ \\
\hline & high & -53.07 & medium-high & $<0.001$ \\
\hline \multirow{3}{*}{ Silesian } & low & -0.57 & low-medium & $<0.001$ \\
\hline & medium & -27.73 & low-high & $<0.001$ \\
\hline & high & -43.47 & medium-high & $<0.001$ \\
\hline \multirow{3}{*}{ Subcarpathian } & low & -1.14 & low-medium & $<0.001$ \\
\hline & medium & -33.93 & low-high & $<0.001$ \\
\hline & high & -51.35 & medium-high & $<0.001$ \\
\hline \multirow{3}{*}{ Warmian-Masurian } & low & 6.95 & low-medium & $<0.001$ \\
\hline & medium & -21.88 & low-high & $<0.001$ \\
\hline & high & -42.63 & medium-high & $<0.001$ \\
\hline & low & 6.52 & low-medium & $<0.001$ \\
\hline West Pomeranian & medium & -19.17 & low-high & $<0.001$ \\
\hline & high & -42.43 & medium-high & $<0.001$ \\
\hline
\end{tabular}

Source: own calculations using R based on data from Google COVID-19 Community Mobility Reports (Google 2020) and the Oxford COVID-19 Government Response Tracker (Hale et al. 2020). 

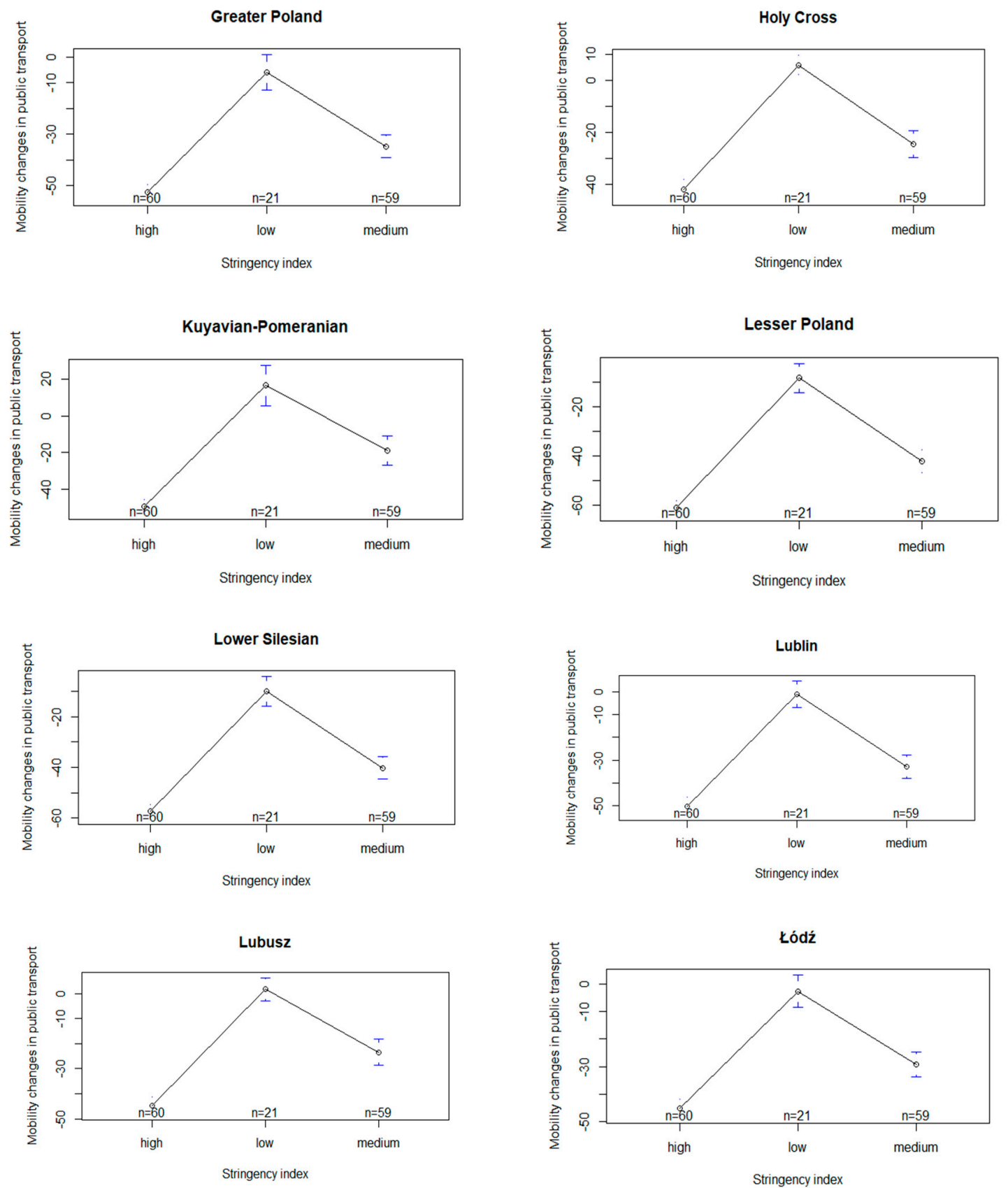

(a)

Figure A3. Cont. 

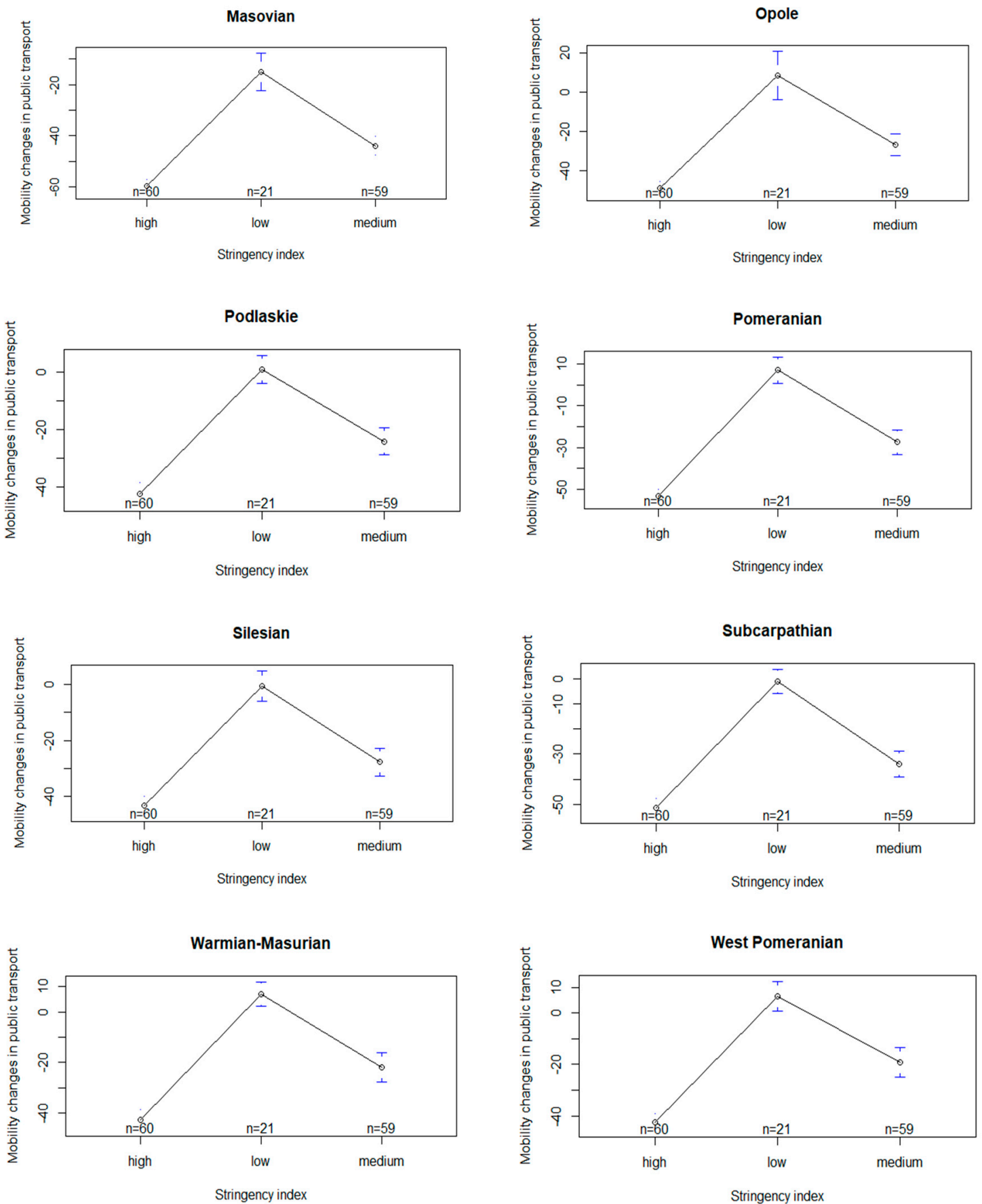

(b)

Figure A3. (a) The mean changes in mobility in public transport at three levels of the stringency of Polish government's anti-COVID-19 policy in Polish voivodeships from 2 March to 19 July 2020. Source: own calculations using R based on data from Google COVID-19 Community Mobility Reports (Google 2020) and the Oxford COVID-19 Government Response Tracker (Hale et al. 2020). (b) The mean changes in mobility in public transport at three levels of the stringency of Polish government's anti-COVID-19 policy in Polish voivodeships from 2 March to 19 July 2020. Source: own calculations using R based on data from Google COVID-19 Community Mobility Reports (Google 2020) and the Oxford COVID-19 Government Response Tracker (Hale et al. 2020). 


\section{References}

Almagro, Milena, and Angelo Orane-Hutchinson. 2020. The Differential Impact of COVID-19 across Demographic Groups: Evidence from NYC. SSRN Electronic Journal. [CrossRef]

Aloi, Alfredo, Borja Alonso, Juan Benavente, Rubén Cordera, Eneko Echániz, Felipe González, Claudio Ladisa, Raquel Lezama-Romanelli, Álvaro López-Parra, Vittorio Mazzei, and et al. 2020. Effects of the COVID-19 Lockdown on Urban Mobility: Empirical Evidence from the City of Santander (Spain). Sustainability 12: 3870. [CrossRef]

Andersen, Kristian, Andrew Rambaut, W. Ian Lipkin, Edward Holmes, and Robert Garry. 2020. The proximal origin of SARS-CoV-2. Nature Medicine 26: 450-52. [CrossRef] [PubMed]

Askitas, Nikos, Konstantinos Tatsiramos, and Bertrand Verheyden. 2020. Lockdown Strategies, Mobility Patterns and COVID-19. arXiv arXiv:2006.00531.

Badr, Hamada S., Hongru Du, Maximilian Marshall, Ensheng Dong, Marietta M. Squire, and Lauren M. Gardner. 2020. Association between Mobility Patterns and COVID-19 Transmission in the USA: A Mathematical Modelling Study. The Lancet Infectious Diseases. [CrossRef]

Bajardi, Paolo, Chiara Poletto, Jose J. Ramasco, Michele Tizzoni, Vittoria Colizza, and Alessandro Vespignani. 2011. Human Mobility Networks, Travel Restrictions, and the Global Spread of 2009 H1N1 Pandemic. Edited by Matjaz Perc. PLoS ONE 6: e16591. [CrossRef]

Barro, Robert, José Ursúa, and Joanna Weng. 2020. The Coronavirus and the Great Influenza Pandemic: Lessons from the "Spanish Flu" for the Coronavirus's Potential Effects on Mortality and Economic Activity. NBER Working Papers 26866. National Bureau of Economic Research, Cambridge, MA, USA. [CrossRef]

Bonaccorsi, Giovanni, Francesco Pierri, Matteo Cinelli, Andrea Flori, Alessandro Galeazzi, Francesco Porcelli, Ana Lucia Schmidt, Carlo Michele Valensise, Antonio Scala, Walter Quattrociocchi, and et al. 2020. Economic and Social Consequences of Human Mobility Restrictions under COVID-19. Proceedings of the National Academy of Sciences 117: 15530-35. [CrossRef]

Boot, Arnoud, Elena Carletti, Rainer Haselmann, Hans-Helmut Kotz, Jan Pieter Krahnen, Loriana Pelizzon, Stephen Schaefer, and Marti Subrahmanyam. 2020. The Coronavirus and Financial Stability. SAFE Policy Letter 78. Frankfurt: Leibniz Institute for Financial Research SAFE.

Browne, Annie, Sacha St-Onge Ahmad, Charles R. Beck, and Jonathan S. Nguyen-Van-Tam. 2016. The Roles of Transportation and Transportation Hubs in the Propagation of Influenza and Coronaviruses: A Systematic Review. Journal of Travel Medicine 23: tav002. [CrossRef]

Cartenì, Armando, Luigi Di Francesco, and Maria Martino. 2020. How Mobility Habits Influenced the Spread of the COVID-19 Pandemic: Results from the Italian Case Study. Science of the Total Environment 741: 140489. [CrossRef]

Chancellery of the Prime Minister of Poland. 2020. Available online: https://www.premier.gov.pl/en/news.html (accessed on 31 July 2020).

Chinazzi, Matteo, Jessica T. Davis, Marco Ajelli, Corrado Gioannini, Maria Litvinova, Stefano Merler, Ana Pastore y Piontti, Kunpeng Mu, Luca Rossi, Kaiyuan Sun, and et al. 2020. The Effect of Travel Restrictions on the Spread of the 2019 Novel Coronavirus (COVID-19) Outbreak. Science 368: 395-400. [CrossRef]

Cochrane, John. 2020. Coronavirus Monetary Policy. In Economics in the Time of COVID-19. Edited by Richard Baldwin and Beatrice di Mauro. London: CEPR Press.

Coven, Joshua, and Arpit Gupta. 2020. Disparities in Mobility Responses to Covid-19. NYU Stern Working Paper. NYU Stern School of Business, New York, NY, USA.

Czech, Katarzyna, Michał Wielechowski, Pavel Kotyza, Irena Benešová, and Adriana Laputková. 2020. Shaking Stability: COVID-19 Impact on the Visegrad Group Countries' Financial Markets. Sustainability 12: 6282. [CrossRef]

De Vos, Jonas. 2020. The Effect of COVID-19 and Subsequent Social Distancing on Travel Behavior. Transportation Research Interdisciplinary Perspectives 5: 100121. [CrossRef]

Eichenbaum, Martin, Sergio Rebelo, and Mathias Trabandt. 2020. The Macroeconomics of Epidemics. NBER Working Papers 26882. National Bureau of Economic Research, Cambridge, MA, USA. [CrossRef]

Engle, Samuel, John Stromme, and Anson Zhou. 2020. Staying at Home: Mobility Effects of COVID-19. SSRN Electronic Journal. [CrossRef] 
Eubank, Stephen, Hasan Guclu, V. S. Anil Kumar, Madhav V. Marathe, Aravind Srinivasan, Zoltán Toroczkai, and Nan Wang. 2004. Modelling Disease Outbreaks in Realistic Urban Social Networks. Nature 429: 180-84. [CrossRef] [PubMed]

Galeazzi, Alessandro, Matteo Cinelli, Giovanni Bonaccorsi, Francesco Pierri, Ana Lucia Schmidt, Antonio Scala, Fabio Pammolli, and Walter Quattrociocchi. 2020. Human Mobility in Response to COVID-19 in France, Italy and UK. arXiv arXiv:2005.06341.

Glaeser, Edward L., Caitlin S. Gorback, and Stephen J. Redding. 2020. How Much does COVID-19 Increase with Mobility? Evidence from New York and Four Other U.S. Cities. National Bureau of Economic Research. [CrossRef]

Goniewicz, Krzysztof, Amir Khorram-Manesh, Attila J. Hertelendy, Mariusz Goniewicz, Katarzyna Naylor, and Frederick M. Burkle. 2020. Current Response and Management Decisions of the European Union to the COVID-19 Outbreak: A Review. Sustainability 12: 3838. [CrossRef]

Goodell, John W. 2020. COVID-19 and Finance: Agendas for Future Research. Finance Research Letters 35: 101512. [CrossRef]

Google. 2020. COVID-19 Community Mobility Reports. Available online: https://www.google.com/covid19/ mobility/ (accessed on 31 July 2020).

Goscé, Lara, and Anders Johansson. 2018. Analysing the Link between Public Transport Use and Airborne Transmission: Mobility and Contagion in the London Underground. Environmental Health 17: 84. [CrossRef]

Gössling, Stefan, Daniel Scott, and C. Michael Hall. 2020. Pandemics, Tourism and Global Change: A Rapid Assessment of COVID-19. Journal of Sustainable Tourism, 1-20. [CrossRef]

Hale, Thomas, Sam Webster, Anna Petherick, Toby Phillips, and Beatriz Kira. 2020. Oxford COVID-19 Government Response Tracker. Blavatnik School of Government. 2020. Available online: www.bsg.ox.ac.uk/covidtracker (accessed on 31 July 2020).

IEA. 2020. Changes in Transport Behaviour during the Covid-19 Crisis. Paris: IEA.

Jelnov, Pavel. 2020. Confronting COVID-19 Myths: Morbidity and Mortality. GLO Discussion Paper 516. Global Labor Organization (GLO).

Jinjarak, Yothin, Rashad Ahmed, Sameer Nair-Desai, Weining Xin, and Joshua Aizenman. 2020. Accounting for Global COVID-19 Diffusion Patterns, January-April 2020. NBER Working Papers 27185. National Bureau of Economic Research, Cambridge, MA, USA. [CrossRef]

Jones, Callum, Thomas Philippon, and Venky Venkateswaran. 2020. Optimal Mitigation Policies in a Pandemic: Social Distancing and Working from Home. NBER Working Papers 26984. National Bureau of Economic Research, Cambridge, MA, USA. [CrossRef]

Kraemer, Moritz UG, Chia-Hung Yang, Bernardo Gutierrez, Chieh-Hsi Wu, Brennan Klein, David M. Pigott, Louis Du Plessis, Nuno R. Faria, Ruoran Li, William P. Hanage, and et al. 2020. The Effect of Human Mobility and Control Measures on the COVID-19 Epidemic in China. Science 368: 493-97. [CrossRef] [PubMed]

Laing, Timothy. 2020. The Economic Impact of the Coronavirus 2019 (Covid-2019): Implications for the Mining Industry. The Extractive Industries and Society 7: 580-82. [CrossRef] [PubMed]

Lau, J T F. 2003. Monitoring Community Responses to the SARS Epidemic in Hong Kong: From Day 10 to Day 62. Journal of Epidemiology \& Community Health 57: 864-70. [CrossRef]

Linka, Kevin, Mathias Peirlinck, Francisco Sahli Costabal, and Ellen Kuhl. 2020. Outbreak Dynamics of COVID-19 in Europe and the Effect of Travel Restrictions. Computer Methods in Biomechanics and Biomedical Engineering 23: 1-8. [CrossRef]

Maier, Benjamin F., and Dirk Brockmann. 2020. Effective Containment Explains Subexponential Growth in Recent Confirmed COVID-19 Cases in China. Science 368: 742-46. [CrossRef]

Mazzoleni, Stefano, Giuseppe Turchetti, and Nicolino Ambrosino. 2020. The COVID-19 Outbreak: From "Black Swan" to Global Challenges and Opportunities. Pulmonology 26: 117-18. [CrossRef]

Ministry of Health of the Republic of Poland. 2020. Available online: https://twitter.com/MZ_GOV_PL (accessed on 31 July 2020).

Morawska, Lidia, Julian W. Tang, William Bahnfleth, Philomena M. Bluyssen, Atze Boerstra, Giorgio Buonanno, Junji Cao, Stephanie Dancerh, Andres Flotoi, Francesco Franchimon, and et al. 2020. How Can Airborne Transmission of COVID-19 Indoors Be Minimised? Environment International 142: 105832. [CrossRef] 
Muller, Sebastian Alexander, Michael Balmer, Andreas Neumann, and Kai Nagel. 2020. Mobility Traces and Spreading of COVID-19. medRxiv. [CrossRef]

Musselwhite, Charles, Erel Avineri, and Yusak Susilo. 2020. Editorial JTH 16 -The Coronavirus Disease COVID-19 and Implications for Transport and Health. Journal of Transport $\mathcal{E}$ Health 16: 100853. [CrossRef]

Nicola, Maria, Zaid Alsafi, Catrin Sohrabi, Ahmed Kerwan, Ahmed Al-Jabir, Christos Iosifidis, Maliha Agha, and Riaz Agha. 2020. The Socio-Economic Implications of the Coronavirus Pandemic (COVID-19): A Review. International Journal of Surgery 78: 185-93. [CrossRef]

Oztig, Lacin Idil, and Oykum Esra Askin. 2020. Human Mobility and Coronavirus Disease 2019 (COVID-19): A Negative Binomial Regression Analysis. Public Health 185: 364-67. [CrossRef] [PubMed]

Peak, Corey M., Amy Wesolowski, Elisabeth zu Erbach-Schoenberg, Andrew J. Tatem, Erik Wetter, Xin Lu, Daniel Power, Elaine Weidman-Grunewald, Sergio Ramos, Simon Moritz, and et al. 2018. Population Mobility Reductions Associated with Travel Restrictions during the Ebola Epidemic in Sierra Leone: Use of Mobile Phone Data. International Journal of Epidemiology 47: 1562-70. [CrossRef] [PubMed]

Pepe, Emanuele, Paolo Bajardi, Laetitia Gauvin, Filippo Privitera, Brennan Lake, Ciro Cattuto, and Michele Tizzoni. 2020. COVID-19 Outbreak Response, a Dataset to Assess Mobility Changes in Italy Following National Lockdown. Scientific Data 7: 230. [CrossRef]

Pullano, Giulia, Eugenio Valdano, Nicola Scarpa, Stefania Rubrichi, and Vittoria Colizza. 2020. Population Mobility Reductions during COVID-19 Epidemic in France under Lockdown. medRxiv. [CrossRef]

Queiroz, Lucas, Lucas Queiroz, José Luciano Melo, Gabriel Barboza, Alysson H. Urbanski, André Nicolau, Sergio Oliva, and Helder Nakaya. 2020. Large-Scale Assessment of Human Mobility during COVID-19 Outbreak. Open Science Framework Open Science Framework. Open Science Framework. [CrossRef]

Ritchie, Hannah. 2020. Google Mobility Trends: How Has the Pandemic Changed the Movement of People around the World? Available online: https://ourworldindata.org/covid-mobility-trends (accessed on 31 July 2020).

Schlosser, Frank, Benjamin F. Maier, David Hinrichs, Adrian Zachariae, and Dirk Brockmann. 2020. COVID-19 Lockdown Induces Structural Changes in Mobility Networks-Implication for Mitigating Disease Dynamics. arXiv arXiv:2007.01583.

Service of the Republic of Poland. 2020. Available online: https://www.gov.pl/web/coronavirus (accessed on 31 July 2020).

Statista. 2020. Available online: https://www.statista.com/statistics/1112658/poland-transport-of-passengersduring-covid-19-by-transport-type (accessed on 31 July 2020).

Tian, Huaiyu, Yonghong Liu, Yidan Li, Chieh-Hsi Wu, Bin Chen, Moritz U. G. Kraemer, Bingying Li, Jun Cai, Bo Xu, Qiqi Yang, and et al. 2020. An Investigation of Transmission Control Measures during the First 50 Days of the COVID-19 Epidemic in China. Science 368: 638-42. [CrossRef]

Tirachini, Alejandro, and Oded Cats. 2020. COVID-19 and Public Transportation: Current Assessment, Prospects, and Research Needs. Journal of Public Transportation 22: 1. [CrossRef]

Troko, Joy, Puja Myles, Jack Gibson, Ahmed Hashim, Joanne Enstone, Susan Kingdon, Christopher Packham, Shahid Amin, Andrew Hayward, and Jonathan Nguyen Van-Tam. 2011. Is Public Transport a Risk Factor for Acute Respiratory Infection? BMC Infectious Diseases 11: 16. [CrossRef]

Wang, Kuo-Ying. 2014. How Change of Public Transportation Usage Reveals Fear of the SARS Virus in a City. Edited by Volker Thiel. PLoS ONE 9: e89405. [CrossRef]

Warren, Michael S., and Samuel W. Skillman. 2020. Mobility Changes in Response to COVID-19. arXiv arXiv:2003.14228.

Wind, Tim R., Marleen Rijkeboer, Gerhard Andersson, and Heleen Riper. 2020. The COVID-19 Pandemic: The “Black Swan" for Mental Health Care and a Turning Point for e-Health. Internet Interventions 20: 100317. [CrossRef] [PubMed]

Wu, Joseph T., Kathy Leung, and Gabriel M. Leung. 2020. Nowcasting and Forecasting the Potential Domestic and International Spread of the 2019-NCoV Outbreak Originating in Wuhan, China: A Modelling Study. The Lancet 395: 689-97. [CrossRef]

Yap, Bee Wah, and Chiaw Hock Sim. 2011. Comparisons of Various Types of Normality Tests. Journal of Statistical Computation and Simulation 81: 2141-55. [CrossRef]

Yilmazkuday, Hakan. 2020. Stay-at-Home Works to Fight against COVID-19: International Evidence from Google Mobility Data. SSRN Electronic Journal. [CrossRef] 
Yuksel, Mutlu, Yigit Aydede, and Francisko Begolli. 2020. Dynamics of Social Mobility during the COVID-19 Pandemic in Canada. IZA Discussion Paper No. 13376. Available online: https://ssrn.com/abstract=3631586 (accessed on 31 July 2020).

Zheng, Ruizhi, Yu Xu, Weiqing Wang, Guang Ning, and Yufang Bi. 2020. Spatial Transmission of COVID-19 via Public and Private Transportation in China. Travel Medicine and Infectious Disease 34. [CrossRef] [PubMed] 